\title{
Patients with heart failure and concomitant chronic obstructive pulmonary disease participating in the Heart Failure Pilot Survey (ESC-HF Pilot) - Polish population
}

\author{
Ewa Straburzyńska-Migaj ${ }^{1}$, Marta Kałużna-Oleksy' ${ }^{1}$, Aldo Pietro Maggioni², Stefan Grajek ${ }^{1}$, \\ Grzegorz Opolski ${ }^{3}$, Piotr Ponikowski ${ }^{4}$, Ewa Jankowska ${ }^{4}$, Paweł Balsam³ ${ }^{3}$ Lech Poloński ${ }^{5}$, \\ Jarosław Drożdż
}

\begin{abstract}
${ }^{1} 1^{\text {st }}$ Department of Cardiology, University Hospital “Przemienienia Pańskiego”, Poznan University of Medical Sciences, Poznan, Poland

${ }^{2}$ ANMCO Research Center, Florence, Italy

${ }^{3} 1^{\text {st }}$ Department of Cardiology, Medical University of Warsaw, Warsaw, Poland ${ }^{4}$ Department of Cardiology, $4^{\text {th }}$ Military Hospital, Medical University of Wroclaw, Wroclaw, Poland

${ }^{5} 3^{\text {rd }}$ Chair and Department of Cardiology, Silesian Centre for Heart Diseases, Medical University of Silesia in Katowice, Medical Faculty in Zabrze, Poland ${ }^{6}$ Department of Cardiology, Medical University of Lodz, Lodz, Poland
\end{abstract}

Submitted: 24 March 2014

Accepted: 5 June 2014

Arch Med Sci 2015; 11, 4: 743-750

DOI: 10.5114 /aoms.2014.47878

Copyright (C) 2015 Termedia \& Banach

\section{Abstract}

Introduction: There is an increasing interest in comorbidities in heart failure patients. Data about chronic obstructive pulmonary disease (COPD) in the Polish population of heart failure (HF) patients are scarce. The aim of this study was to investigate the clinical characteristics, treatment differences and outcome according to COPD occurrence in the Polish population of patients participating in the ESC-HF Pilot Survey Registry.

Material and methods: We analyzed the data of 891 patients with HF recruited in 2009-2011 in Poland: 648 (72.7\%) hospitalized patients and 243 (27.3\%) patients included as outpatients.

Results: The COPD was documented in 110 (12.3\%) patients with HF in the analyzed population. Patients with - compared to those without COPD were older, more often smokers, had higher NYHA class, and higher prevalence of hypertension. Ejection fraction (EF) was higher in hospitalized patients with COPD compared to patients without COPD ( $40.5 \pm 14.6 \%$ vs. $37.2 \pm 13.7 \%$, $p<0.04)$, without a significant difference in the outpatient group. There was a significant difference in $\beta$-blocker use between patients with and without COPD $(81.8 \%$ vs. $94.7 \%, p<0.0001)$. Most patients received them below target doses. At the end of the 12-month follow-up, there was no significant difference in mortality between COPD and no-COPD patients $(10.9 \%$ vs. $11.1 \%, p=0.66$ ).

Conclusions: The findings from the Polish part of the ESC-HF registry indicate that COPD in patients with HF is associated with older age, smoker status, hypertension and higher NYHA class. The use of $\beta$-blockers was significantly lower in patients with than without COPD. There were no significant differences in mortality between groups.

Key words: $\beta$-blocker, chronic heart failure, chronic obstructive pulmonary disease.

\author{
Corresponding author: \\ Prof. Ewa Straburzyńska-Migaj \\ MD, PhD \\ $1^{\text {st }}$ Department of Cardiology \\ University Hospital \\ "Przemienienia Pańskiego" \\ Poznan University \\ of Medical Sciences \\ $1 / 2$ Długa St \\ 61-848 Poznan, Poland \\ Phone: +48 618549146 \\ E-mail: ewa.straburzynska- \\ migaj@skpp.edu.pl
}




\section{Introduction}

Chronic obstructive pulmonary disease (COPD) is a common comorbidity in about $30 \%$ of patients with heart failure (HF) [1]. Some reports indicate that coexistence of COPD in patients with HF may even reach $40 \%$ [2]. And ca. $30 \%$ of patients with clinically stable COPD present different stages of heart failure (left ventricle HF) [3]. Studies of concomitant COPD and HF consider mostly patients with decompensated $\operatorname{HF}[4,5]$ hospitalized in specialized heart failure departments [2], or those who participate in trials $[6,7]$. Only a few consider stable patients or those undergoing outpatient treatment $[8,9]$. The impact of both these chronic diseases on clinical outcomes and on the course of treatment is unclear. Several studies report worse outcomes in patients with HF and COPD [10-12] whereas others have been neutral $[9,13,14]$.

It is known that chronic HF is associated with significant mortality and morbidity, and worse quality of life. Estimates show that patients with concomitant $\mathrm{HF}$ and COPD require more medical visits than patients with only one of these diseases [8]. An important therapeutic problem in patients with HF and concomitant COPD is $\beta$-blocker use. Many clinicians hesitate to use them or increase dosage in COPD patients [15-17]. Safety of cardioselective $\beta$-blockers in COPD has been proved in numerous trials [18-20]. However, the impact of $\beta$-blocker selectivity in patients with concomitant $\mathrm{HF}$ and COPD is not well characterized [9, 21, 22]. $\beta$-Blockers, particularly non-cardioselective ones, may cause bronchospasm or reduce the benefit of an inhaled $\beta$-2 agonist [23].

The Heart Failure Pilot Survey (ESC-HF Pilot) registry was conducted by the Heart Failure Association of the European Society of Cardiology in order to collect current data on epidemiology, diagnostics and therapeutic processes in patients with HF in European countries [24]. This registry shows the organization of long-term care of HF patient in European countries.

Data about COPD in the Polish population of HF patients are scarce.

Our aim was to compare the baseline characteristics and long-term outcomes of patients with $\mathrm{HF}$, with and without COPD, in the Polish patients enrolled in the Heart Failure Pilot Registry. The secondary aim was to analyze $\beta$-blocker treatment in patients with HF, with and without COPD.

\section{Material and methods}

The ESC Heart Failure Pilot Survey registry was a multicenter, prospective observational study conducted in 2009-2011. It included 136 centers from 12 European countries [24, 25]. The details of methods are described elsewhere [24]. For this registry, all outpatients with $\mathrm{HF}$ seen at the clinics and in patients admitted for acute HF were enrolled during 1 day per week for 8 consecutive months and followed up for 1 year. The HF was diagnosed by cardiologists of the participating centers according to their clinical judgment. Patients with acute HF who required an intravenous therapy were enrolled. The cut-off value of LVEF was not pre-specified. A questionnaire was completed for each patient. It included general clinical characteristics, etiology of HF, co-morbidities, basic biochemical parameters, and treatment used before and after inclusion in the study. Clinical evaluation also included laboratory tests, echocardiography, cardiopulmonary exercise testing (CPX) with pulmonary function testing, electrocardiography, and chest X-ray, if performed. B-type natriuretic peptide (BNP) was available only for some patients (7\%); thus a significant statistical analysis of this parameter was impossible. All patients received stable pharmacological treatment. We analyzed the data of 891 patients included between October 2009 and May 2010 in the Polish part of the registry. Data of inpatients were collected at hospital discharge $(n=648 ; 72.7 \%)$ and of outpatients at medical visits ( $n=243 ; 27.3 \%)$. Chronic obstructive pulmonary disease was reported by the clinical investigator based on clinical evidence and/or treatment for COPD. Pulmonary function testing was not routinely performed. GOLD status was unavailable. All patients had 12-month follow-up.

The Heart Failure Pilot Registry was approved by the National Ethic Committee, and all enrolled patients provided written informed consent.

\section{Statistical analysis}

A statistical software package (Statistica) was used for all analyses. All continuous data are reported as mean values \pm standard deviation (SD), and all categorical variables are reported as percentages. Baseline characteristics in the populations were compared using the Mann-Whitney $U$-test for continuous variables and the $\chi^{2}$ test for categorical variables. Time-to-event curves for the investigated groups (COPD/non-COPD) show 12-month mortality using the Kaplan-Meier method and log-rank test. All tests were two-sided. Statistical differences with a $p$ value $<0.05$ were considered significant.

\section{Results}

In the analyzed HF population $(n=891)$ COPD was demonstrated in $12.3 \%(n=110)$. The majority of participants were hospitalized due to worsening of chronic HF or acute HF (72.95\%). There were no significant differences in the numbers of hospitalized patients with and without COPD 
Table I. Baseline characteristics in HF patients according to COPD status

\begin{tabular}{|c|c|c|c|}
\hline Variable & No COPD $(n=781)$ & $\operatorname{COPD}(n=110)$ & Value of $p$ \\
\hline Age [years] & $65.5 \pm 13.4$ & $70.4 \pm 11.4$ & 0.00002 \\
\hline Male sex (\%) & 65.6 & 71.8 & NS \\
\hline NYHA class & $2.7 \pm 0.8$ & $2.9 \pm 0.7$ & 0.016 \\
\hline Ischemic etiology (\%) & 56.7 & 56.4 & NS \\
\hline Smoking currently/previous (\%) & 57.3 & 72 & 0.002 \\
\hline Diabetes mellitus (\%) & 33.4 & 31.8 & NS \\
\hline Hypertension (\%) & 61.9 & 75.5 & 0.001 \\
\hline Chronic kidney disease (\%) & 18.6 & 24.5 & NS \\
\hline Depression (\%) & 3 & 3.6 & NS \\
\hline Atrial fibrillation/flutter (\%) & 40.2 & 42.7 & NS \\
\hline Hemoglobin $(n=635)[\mathrm{mg} / \mathrm{dl}]$ & $13.3 \pm 2.0$ & $13.1 \pm 2.1$ & NS \\
\hline Creatinine $(n=619)[\mu \mathrm{mol} / \mathrm{dl}]$ & $106.2 \pm 54$ & $114.8 \pm 62.2$ & 0.078 \\
\hline \multicolumn{4}{|l|}{ Pharmacotherapy (\%): } \\
\hline ACEI/ARB & 88.2 & 88.4 & NS \\
\hline$\beta$-Blockers & 94.7 & 81.8 & $<0.0001$ \\
\hline Aldosterone antagonists & 67.3 & 64.9 & NS \\
\hline Diuretics & 88.2 & 84.6 & NS \\
\hline Digoxin & 30.9 & 27.6 & NS \\
\hline Statin & 64.6 & 67.7 & NS \\
\hline Antiplatelet drugs & 66.4 & 67.7 & NS \\
\hline Amiodarone & 9 & 6.4 & NS \\
\hline
\end{tabular}

COPD - chronic obstructive pulmonary disease, HF - heart failure, NYHA - New York Heart Association, ACEI - angiotensin-converting enzyme inhibitor, $A R B$ - angiotensin II receptor blocker

(74.55\% vs. $72.47 \%, p>0.3)$. We analyzed only the stable period of the HF - at hospital discharge or outpatient treatment.

Baseline characteristics are shown in Table I. Patients with COPD were significantly older and had higher NYHA class compared with those without COPD (Figure 1). There were no differences as to sex or incidence of ischemic etiology of heart failure. Patients with COPD more often had a history of smoking. They also more often had atrial fibrillation, chronic kidney disease, depression and hypertension, but only the difference in hypertension incidence was statistically significant. Additional data are shown in Table II. There were no significant differences in blood pressure, heart rate or occurrence of pulmonary rales, or in ECG parameters such as QRS and QT duration. Basic laboratory test results were similar in the investigated groups. Left ventricle ejection fraction (LVEF) was higher in hospitalized HF COPD(+) patients than HF COPD(-), which was not observed in ambulatory groups.
There were no significant differences in the use of ACEI/ARB or aldosterone antagonists, but patients with COPD were less likely to receive $\beta$-blockers, although use of $\beta$-blockers was quite high - in more than $80 \%$ of patients. Patients with

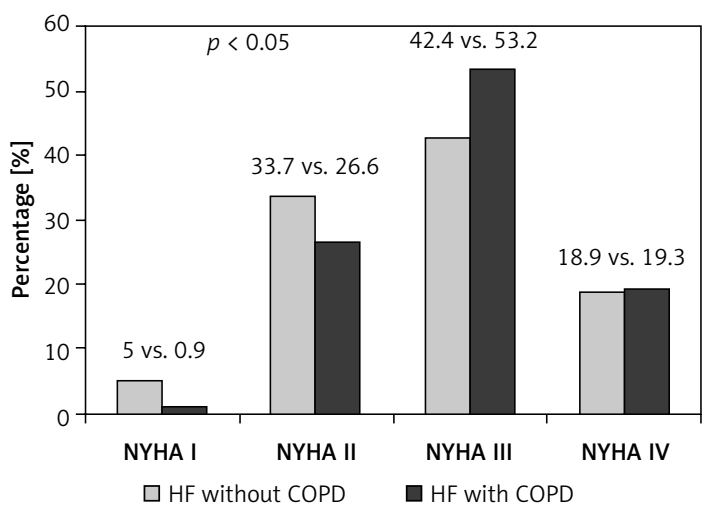

Figure 1. HF severity according to NYHA class in patients $\operatorname{COPD}(+)$ compared to $\operatorname{COPD}(-)$ et the entry of the registry 
Table II. Additional examination data - hospitalized and outpatients

\begin{tabular}{|lcccccc|}
\hline Variable & \multicolumn{3}{c}{ Hospitalized patients } & \multicolumn{3}{c|}{ Outpatients } \\
\cline { 2 - 7 } & $\begin{array}{c}\text { No COPD } \\
(n=566)\end{array}$ & $\begin{array}{c}\text { COPD } \\
(n=82)\end{array}$ & Value of $p$ & $\begin{array}{c}\text { No COPD } \\
(n=215)\end{array}$ & $\begin{array}{c}\text { COPD } \\
(n=28)\end{array}$ & Value of $p$ \\
\hline LVEDD $[\mathrm{mm}]$ & $58.2 \pm 11.3$ & $56.2 \pm 11$ & NS & $59.1 \pm 10.1$ & $58.2 \pm 8.6$ & NS \\
\hline LVEF $(\%)$ & $37.2 \pm 13.7$ & $40.5 \pm 14.6$ & 0.035 & $41.4 \pm 14.3$ & $40.1 \pm 11.2$ & NS \\
\hline $\begin{array}{l}\text { Systolic blood pressure } \\
\text { [mm Hg] }\end{array}$ & $133.5 \pm 28.7$ & $132.4 \pm 23.7$ & NS & $130 \pm 20$ & $131 \pm 18.9$ & NS \\
\hline Heart rate $[\mathrm{beats} / \mathrm{min}]$ & $76.5 \pm 15.5$ & $74 \pm 12.1$ & NS & $74.7 \pm 15.9$ & $78 \pm 14.2$ & NS \\
\hline Hemoglobin $[\mathrm{mg} / \mathrm{dl}]$ & $13 \pm 2.1$ & $12.4 \pm 2$ & NS & $13.3 \pm 2.3$ & $13.7 \pm 2.5$ & NS \\
\hline Creatinine $[\mu \mathrm{mol} / \mathrm{dl}]$ & $110.3 \pm 59.8$ & $120.3 \pm 67.4$ & 0.073 & $93.6 \pm 26.1$ & $99.0 \pm 40.6$ & NS \\
\hline QRS duration $[\mathrm{ms}]$ & $111.6 \pm 26$ & $110.9 \pm 24.7$ & NS & $103 \pm 22.9$ & $109.5 \pm 33.3$ & NS \\
\hline QT duration $[\mathrm{ms}]$ & $393.3 \pm 48.4$ & $397 \pm 46$ & NS & $394.3 \pm 42.5$ & $387.1 \pm 54.3$ & NS \\
\hline
\end{tabular}

Table III. $\beta$-Blocker therapy according to COPD coexistence

\begin{tabular}{|lccc|}
\hline & $\begin{array}{c}\text { No COPD } \\
(n=781)\end{array}$ & $\begin{array}{c}\text { COPD } \\
(n=110)\end{array}$ & $\begin{array}{c}\text { Value } \\
\text { of } p\end{array}$ \\
\hline$\beta$-Blockers (\%) & 94.7 & 81.8 & 0.0001 \\
\hline Cardioselective (\%) & 40.97 & 43.36 & NS \\
\hline
\end{tabular}

COPD were more likely to receive cardioselective than non-cardioselective $\beta$-blockers in comparison to those without COPD $(43.36 \%$ vs. $40.97 \%$; $p=0.14)$ (Table III). The use of nebivolol was significantly higher in COPD patients $(10 \%$ vs. $1.3 \%$; $p<0.0000)$. The differences in use of bisoprolol (COPD vs. no COPD, respectively: $24.6 \%$ vs. $21.9 \%$; $p=0.29)$ and metoprolol were not significant (COPD vs. no COPD, respectively: $11.8 \%$ vs. $17.7 \%$; $p=0.13)$. Analysis of use of different agents showed that although carvedilol was the most frequently used $\beta$-blocker, patients with COPD received it significantly less frequently (Table IV). The patients with COPD received lower doses of carvedilol, bisoprolol and atenolol, although the differences were not significant, and median doses were the same as in patients without COPD (Table IV). Target doses of carvedilol (50 mg/day) were used in only $18 \%$ of $\operatorname{COPD}(-)$ patients vs. $8 \%$ of $\operatorname{COPD}(+)$ patients $(p=N S)$, of bisoprolol (10 mg/day) in $13 \%$ vs. $0 \%(p=0.052)$, of metoprolol (200 mg/day) in $2.2 \%$ vs. $7.7 \%(p=N S)$, and nebivolol (10 mg/day) in $10 \%$ vs. $10 \%$ ( $p=\mathrm{NS})$.

During the 12-month follow-up 12 patients $(10.9 \%)$ died in the COPD group and 87 patients $(11.1 \%)$ in the non-COPD group $(p=0.66)$. Figure 2 shows Kaplan-Meier curves for 12-month all-cause mortality. We did not observe significant differences in clinical status represented as

Table IV. $\beta$-Blocker therapy characteristics - different agents according to COPD coexistence

\begin{tabular}{|c|c|c|c|}
\hline Therapy & No COPD $(n=781)$ & $\operatorname{COPD}(n=110)$ & Value of $p$ \\
\hline Carvedilol (\%) & 50.5 & 31.8 & 0.00025 \\
\hline Carvedilol mean dose [mg] & $22.7 \pm 18.1$ & $18.6 \pm 18.6$ & NS \\
\hline Median dose [mg] & 12.5 & 12.5 & \\
\hline Metoprolol (\%) & 17.7 & 11.8 & NS \\
\hline Metoprolol mean dose [mg] & $64.6 \pm 37.2$ & $88.5 \pm 68.2$ & NS \\
\hline Median dose [mg] & 50 & 50 & \\
\hline Bisoprolol (\%) & 21.9 & 24.6 & NS \\
\hline Bisoprolol mean dose [mg] & $6.4 \pm 12.0$ & $3.9 \pm 1.64$ & NS \\
\hline Median dose $[\mathrm{mg}]$ & 5.0 & 5.0 & \\
\hline Nebivolol (\%) & 1.3 & 10 & $<0.00001$ \\
\hline Nebivolol mean dose [mg] & $5.63 \pm 2.8$ & $4.5 \pm 2.3$ & NS \\
\hline Median dose [mg] & 5.0 & 5.0 & \\
\hline Others (\%) & 3.3 & 4.4 & NS \\
\hline
\end{tabular}


NYHA class in patients with HF with and without COPD (2.18 \pm 0.67 vs. $2.16 \pm 0.75$ respectively; $p=\mathrm{NS})$. The biochemical parameters were mostly not available, so a statistical analysis was not performed.

\section{Discussion}

The main findings of this study are: 1 . COPD in HF patients is associated with older age, worse NYHA functional class, higher prevalence of hypertension and current or previous smoking; 2 . The use of $\beta$-blockers is quite high in the whole group (more than $80 \%$ ), but significantly lower in patients with COPD; 3 . There are no significant differences in 12-month mortality in HF patients with and without COPD.

To our knowledge this is the first analysis of the Polish population of HF patients with concomitant COPD. The characteristics of HF patients treated by general practitioners in Poland was described in the ZOPAN study, which focused on health status, quality of care, and burden to the healthcare system [26]. Sosnowska-Pasiarska et al. [25] described the Polish population of HF patients in comparison to the European population concerning clinical epidemiology of outpatients and inpatients with HF and currently used diagnostic and therapeutic modalities.

Comorbidity of HF and COPD presents a great diagnostics challenge and causes therapeutic problems. The diagnostic process can be difficult because both conditions share features such as age of development, symptoms of dyspnea and smoking as a risk factor. Our registry demonstrated relatively low incidence of COPD in HF patients in the Polish population (12.3\%). The population studies show the coexistence of HF and COPD up to about $30 \%$ worldwide [1]. Incidence of COPD in the European registry varied from $15.1 \%$ [27] to $16 \%$ [25] and was significantly higher in inpatients $(20.13 \%)$ than in outpatients (13.8\%) [28]. This suggests that COPD may be under-diagnosed in HF patients in the European registry (including in the Polish part) because the diagnosis was based only on medical history or current treatment. Spirometry was not routinely performed. Similarly, the prevalence of COPD was $11 \%$ in stable patients with $\mathrm{HF}$ and LVEF $\leq 35 \%$ from the HF-ACTION study, in which COPD status was prospectively recorded at the study entry by the investigator, based on clinical evidence or knowledge of medical history [9].

Our analysis demonstrated that COPD is associated with older age, worse baseline NYHA functional class, increased incidence of hypertension and smoking history. The HF-ACTION trial also showed that $\operatorname{COPD}(+)$ patients were older, had more concomitant diseases, higher NYHA class,

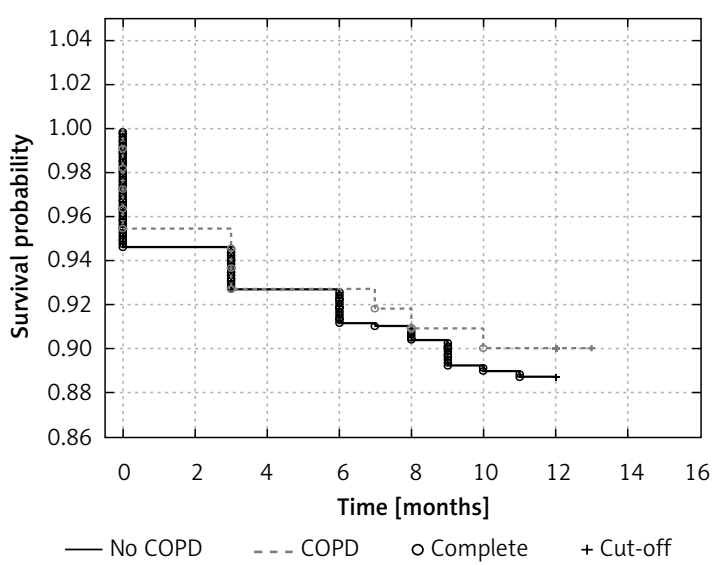

Figure 2. Kaplan-Meier curves for all-cause mortality at 12 -month follow-up

lower use of $\beta$-blockers ( $88 \%$ vs. $94 \%$ ), but there was no difference in mortality [9]. In contrast to some previous studies $[15,16]$ and similarly to HF-ACTION [9], the Polish HF patients with and without COPD from the Heart Failure Pilot Registry had similar basic laboratory values and blood pressure. In the EVERST and OPTIMIZE-HF studies, patients with COPD tended to have lower blood pressure and higher serum creatinine $[15,16]$. The differences may be due, in part, to the relatively stable phase of the disease in our population outpatient phase or hospital discharge. Ejection fraction in HF outpatients with and without COPD was not significantly different. It was higher in inpatients with COPD than in those without COPD. The differences were not very large, but were statistically significant. Probably dyspnea, being the main reason for admission in patients with and without COPD, was similarly severe regardless of its cause (exacerbation of COPD or of HF). Differential diagnostics of acute dyspnea is especially difficult without measurement of biomarkers [29]. Unfortunately, we could not analyze this properly without natriuretic peptide levels and GOLD status. Most studies considered systolic HF and they did not find significant LVEF differences in HF patients with and without COPD $[9,15]$. In the study of prognosis in HF with reduced vs. preserved LVEF and coexistent COPD, no influence of LVEF on prognosis was found [30].

The HF should be treated according to the ESC HF-guidelines, even in COPD patients, because there is no evidence that HF should be treated differently in patients with this comorbidity [31, 32]. $\beta$-Blockers are strongly recommended in all patients with systolic $\operatorname{HF}[32,33]$, including in those with coexistent COPD [34], with cardioselective $\beta$-blockers as the primary choice [21-23]. A lot of trials show that patients with HF and coexistent COPD receive $\beta$-blockers significantly less frequently than those with $\mathrm{HF}$ without $\operatorname{COPD}[8,9$, 
15, 17]. In EVEREST and OPTIMIZE-HF the use of $\beta$-blockers was $\sim 65 \%$ vs. $75 \%$, and in HF-ACTION it was $88 \%$ vs. $95 \%[9,15,16]$. Although a Cochrane meta-analysis concluded that $\beta$-1-selective $\beta$-blockers are safe, only $35 \%$ of patients with chronic HF and COPD received $\beta$-blocker therapy [35]. From the $\beta$-blockers currently recommended in HF therapy, only carvedilol is not cardioselective. Metoprolol, bisoprolol and nebivolol are the best candidates in treatment of HF with concomitant COPD [23].

In contrast to the previous studies [15, 16, 26], the Heart Failure Pilot Registry of the Polish population showed quite high use of $\beta$-blockers in patients with $\mathrm{HF}$, although, similarly to these studies, it was significantly lower in patients with than without COPD. In the detailed analysis of treatment in patients from the European cohort of the ESC$\mathrm{HF}$ Pilot registry, $86.7 \%$ received $\beta$-blockers and the most frequently used was carvedilol (42.8\%) in the median dose of $25 \mathrm{mg} /$ day. Bisoprolol was used in $32.3 \%$ of patients in the median dose of $5 \mathrm{mg} /$ day, and metoprolol was used in $18.9 \%$ in the median dose of $100 \mathrm{mg} /$ day [24]. Our data from the Polish population show that similarly carvedilol was used most frequently, followed by bisoprolol and metoprolol, but the median doses for carvedilol and metoprolol were half of those reported above, and a very low percentage of patients used target doses. The newer European registry reported about $88.9 \%$ use of $\beta$-blockers, with the target dose achieved only in $17.5 \%$ of them [28]. The most common agents were again bisoprolol and carvedilol [28]. In HFACTION the doses of $\beta$-blockers were also significantly lower in COPD patients [9]. The results of the presented studies indicate that guidelines adherence regarding use of recommended drugs is still a problem in patients with HF and concomitant COPD. There is also a problem of up-titrating of the recommended medication to the target doses, especially in the Polish cohort of the registry.

The data regarding prognosis in patients with $\mathrm{HF}$ and COPD are not clear $[2,5,7,15,16]$. In the majority of studies it is worse than in HF or COPD alone. Our analysis revealed no significant differences in mortality during the 12-month follow-up between patients with and without COPD despite higher NYHA class and older age, similarly to HF-ACTION [9]. The higher NYHA class may be related to more severe COPD, but we had no data on GOLD class. It is suggested that incidence of ventricular dysfunction in patients with COPD tends to increase the risk of mortality during follow-up. However, presence of a pulmonary obstruction in patients with chronic HF does not seem to influence survival [36]. Absence of differences in 12-month mortality can be explained by similar ejection fraction in both outpatient groups and even greater LVEF in inpatients with COPD than without.

Our study should be interpreted with caution and in the context of many limitations. The Heart Failure Pilot Registry was performed to collect information about chronic heart failure status in the European population. Collecting the information about concomitant diseases was a secondary aim. A major limitation is that the definition of chronic obstructive pulmonary disease was left to the investigator and was based on the knowledge of medical history or treatment used. Pulmonary function testing was not routinely performed. The data regarding COPD treatment were not recorded. Data were collected by cardiologists, and it is likely that internal medicine specialists observe a higher rate of COPD. Another major limitation is the lack of data on levels of natriuretic peptides, which are important markers of severity of HF and approved prognostic factors.

Based on our data, it seems that pulmonary function testing is necessary in diagnosing COPD, and cardiologists should consider screening for this disease in HF patients. The ESC-HF Pilot survey indicates a high standard of the rate of use of renin-angiotensin-aldosterone system blockers and $\beta$-blockers but at the same time under-dosing of them and unsatisfactory $\beta$-blocker use in $\mathrm{HF}$ and coexisting COPD. Further studies are needed to confirm the long-term results of $\beta$-blockers in patients with HF and COPD.

In conclusion, the presented study is to our best knowledge the first analysis of the Polish population of HF patients with concomitant COPD. The registry shows that the incidence of COPD in Polish patients with $\mathrm{HF}$ is relatively low (12.3\%). The COPD in HF patients is associated with older age, worse NYHA functional class, higher incidence of hypertension and history of smoking. Use of $\beta$-blockers is largely adherent to the current guidelines, but significantly lower in patients with than without COPD and in most patients below target doses. The coexistence of HF and COPD does not influence 12-month mortality.

\section{Conflict of interest}

The authors declare no conflict of interest.

\section{References}

1. Hawkins NM, Petrie MC, Jhund MC, et al. Heart failure and chronic obstructive pulmonary disease: diagnostic pitfalls and epidemiology. Eur J Heart Fail 2009; 11: 130-9.

2. Mascarenhas J, Louren P, Lopes R, et al. Chronic obstructive pulmonary disease in heart failure. Prevalence, therapeutic, and prognostic implications. Am Heart J 2008; 155: 521-5.

3. Rutten FH, Cramer MJ, Grobbee DE, et al. Unrecognized heart failure in elderly patients with stable chronic 
obstructive pulmonary disease. Eur Heart J 2005; 26: 1887-94.

4. Rusinaru D, Saaidi I, Godard S, et al. Impact of chronic obstructive pulmonary disease on long-term outcome of patients hospitalized for heart failure. Am J Cardiol 2008; 101: 353-8.

5. Macchia A, Monte S, Romero M, et al. The prognostic influence of chronic obstructive pulmonary disease in patients hospitalized for chronic heart failure. Eur J Heart Fail 2007; 9: 942-8.

6. Hawkins NM, Huang Z, Pieper KS, et al. Chronic obstructive pulmonary disease is an independent predictor of death but not atherosclerotic events in patients with myocardial infarction: analysis of the Valsartan in The Acute Myocardial Infarction Trial (VALIANT). Eur J Heart Fail 2009; 11: 292-8.

7. Staszewsky L, Wong M, Masson S, et al. Clinical, neurohormonal, and inflammatory markers and overall prog nostic role of chronic obstructive disease in patients with heart failure: data from the Val-HeFT heart failure trial. J Card Fail 2007; 13: 797-804.

8. Hawkins NM, Jhund PS, Simpson CR, et al. Primary care burden and treatment of patients with heart failure and chronic obstructive pulmonary disease in Scotland. Eur J Heart Fail 2010; 12: 17-24.

9. Mentz RJ, Schulte PJ, Fleg JL, et al. Clinical characteristics, response to exercise training, and outcomes in patients with heart failure and chronic obstructive pulmonary disease: Findings from Heart Failure and A Controlled Trial Investigating Outcomes of Exercise TrainNing (HF-ACTION). Am Heart J 2013; 165: 193-9.

10. Lee DS, Austin PC, Rouleau JL, et al. Predicting mortality among patients hospitalized for heart failure: derivation and validation of a clinical model. JAMA 2003; 290: 2581-7.

11. Braunstein JB, Anderson GF, Gerstenblith G, et al. Noncardiac comorbidity increases preventable hospitalizations and mortality among Medicare beneficiaries with chronic heart failure. J Am Coll Cardiol 2003; 42 1226-33.

12. Jong P, Vowinckel E, Liu PP, et al. Prognosis and determinants of survival in patients newly hospitalized for heart failure: a population-based study. Arch Intern Med 2002; 162: 1689-94.

13. O'Connor CM, Abraham WT, Albert NM, et al. Predictors of mortality after discharge in patients hospitalized with heart failure: an analysis from the Organized Program to Initiate Lifesaving Treatment in Hospitalized Patients with Heart Failure (OPTIMIZE-HF). Am Heart J 2008; 156: 662-73.

14. Siirila-Waris K, Laussus J, Merlin J, et al. Characteristics, outcomes, and predictors of 1-year mortality in patients hospitalized for acute heart failure. Eur Heart J 2006; 27: 3011-7.

15. Mentz RJ, Fiuzat M, Wojdyla DM, et al. Clinical characteristics and outcomes of hospitalized heart failure patients with systolic dysfunction and chronic obstructive pulmonary disease: findings from OPTIMIZE-HF. Eur J Heart Fail 2012; 14: 395-403.

16. Mentz RJ, Schmidt PH, Kwasny MJ, et al. The impact of chronic obstructive pulmonary disease in patients hospitalized for worsening heart failure with reduced ejection fraction: an analysis of the EVEREST trial. J Card Fail 2012; 18: 515-23.

17. Dahlström U. Frequent non-cardiac comorbidities in patients with chronic heart failure. Eur J Heart Fail 2005 7: 309-16.
18. Salpeter SR, Ormiston TM, Salpeter EE, et al. Cardioselective beta-blockers for chronic obstructive pulmonary disease: a meta-analysis. Respir Med 2003; 97: 1094-101.

19. van der Woude HJ, Zaagsma J, Postma DS, et al. Detrimental effects of beta-blockers in COPD: a concern for nonselective beta-blockers. Chest 2005; 127: 818-24.

20. Shelton RJ, Rigby AS, Cleland JG. Effect of community heart failure clinic on the uptake of beta-blockers in patients with obstructive airways disease and heart failure. Heart 2006; 92: 331-6.

21. Jabbour A, Macdonald PS, Keogh AM, et al. Differences between beta-blockers in patients with chronic heart failure and chronic obstructive pulmonary disease: a randomized crossover trial. J Am Coll Cardiol 2010; 55: 1780-7.

22. Lainscak M, Podbregar M, Kovacic D, et al. Differences between bisoprolol and carvediolol in patients with chronic heart failure and chronic obstructive pulmonary disease: a randomized trial. Respir Med 2011; 105 (Suppl. 1): S44-9.

23. Hawkins NM, Petrie MC, Macdonald MR, et al. Heart failure and chronic obstructive pulmonary disease the quandary of beta-blockers and beta-agonists. J Am Coll Cardiol 2011; 57: 2127-38.

24. Maggioni AP, Dahlström U, Filippatos G, et al. EURObservational Research Programme: The Heart Failure Pilot Survey (ESC-HF Pilot). Eur J Heart Fail 2010; 12: 1076-84.

25. Sosnowska-Pasiarska B, Bartkowiak R, Wożakowska-Kapłon B, et al. Population of Polish patients participating in the Heart Failure Pilot Survey (ESC-HF Pilot). Kardiol Pol 2013; 71: 234-40.

26. Rywik TM, Kołodziej P, Targoński R, et al. Characteristics of heart failure population in Poland: ZOPAN, a multicentre national programme. Kardiol Pol 2011; 69: 24-31.

27. Maggioni AP, Dahlström U, Filippatos G, et al. EURObservational Research Programme: regional differences and 1-year follow-up results of the Heart Failure Pilot Survey (ESC-HF Pilot). Eur J Heart Fail 2013; 15: 808-17.

28. Maggioni AP, Anker SD, Dahlström U, et al. Are hospitalized or ambulatory patients with heart failure treated in accordance with European Society of Cardiology guidelines? Evidence from 12440 patients of the ESC Heart Failure Long-Term Registry. Eur J Heart Fail 2013; 15: 1173-84.

29. Antczak A, Ciebiada M, Pietras T, et al. Exhaled eicosanoids and biomarkers of oxidative stress in exacerbation of chronic obstructive pulmonary disease. Arch Med Sci 2012; 8: 277-85.

30. Kwon BJ, Kim DB, Jang SW, et al. Prognosis of heart failure patients with reduced and preserved ejection fraction and coexistent chronic obstructive pulmonary disease. Eur J Heart Fail 2010; 12: 1339-44.

31. Global Initiative for Chronic Obstructive Lung Disease. Global Strategy for Diagnosis, Management, and Prevention of COPD. Updated Feb 2013. Available from: http://www.goldcopd.org/Guidelines/guidelines-resources.html.

32. McMurray JJ, Adamopoulos S, Anker SD, et al. ESC guidelines for the diagnosis and treatment of acute and chronic heart failure 2012: the Task Force for the Diagnosis and Treatment of Acute and Chronic Heart Failure 2012 of the European Society of Cardiology. Developed in collaboration with the Heart Failure Association (HFA) of the ESC. Eur Heart I 2012; 33: 1787-847.

33. Hunt SA, Abraham WT, Chin MH, et al. ACC/AHA 2005 Guideline Update for the Diagnosis and Management of Chronic Heart Failure in the Adult: a report of the Amer- 
ican College of Cardiology/American Heart Association Task Force on Practice Guidelines (Writing Committee of Update the 2001 Guidelines for Evaluation and Management of Heart Failure): developed in collaboration with the American College of Chest Physicians and the Interventional Society. Circulation 2005; 12: e154-235.

34. The Heart Failure Society of America. Executive summary: HFSA 2006 comprehensive heart failure practice guideline. J Card Fail 2006; 12: 10-38.

35. Stefan MS, Rothberg MB, Pirya A, et al. Association between beta-blocker therapy and outcomes in patients hospitalized with acute exacerbations of chronic obstructive lung disease with underlying ischemic heart disease, heart failure or hypertension. Thorax 2012; 67: 977-84.

36. Macchia A, Rodriguez Moncalvo JJ, Kleinert M, et al. Unrecognized ventricular dysfunction in COPD. Eur Repir J 2012; 39: 51-8. 